\title{
RiCOEUR O UN HORIZONTE FILOSÓFICO MÁS ALLÁ DE LA MUERTE
}

\section{Jorge Brower}

En los últimos años de su vida, Ricoeur, filósofo fundamental de la segunda parte del siglo XX, con sus trabajos desde la fenomenología hasta la hermenéutica del texto y de la acción, se vuelca, de manera prolija y a la vez amorosa, sobre cuestiones centrales que atraviesan su obra, y que en este breve texto cobran un sentido que liga su filosofía de manera especial con su existencia concreta.

Aún cuando se trata de un conjunto de papeles y documentos incompletos, tal vez, aparentemente inconexos, exponen la potente lucidez de quien, en el ocaso de su vida, reafirma el valor de la existencia desde distintos y a veces distantes tópicos que pueden ser comprendidos como coordenadas centrales de su producción intelectual. Las directrices de este pensamiento invitan al lector a un estado de complicidad con los espacios reflexivos delineados. Ciertamente se trata de una complicidad muy íntima, que nos involucra desde el escenario-horizonte de nuestra propia vida, su limitación-finitud y el diseño simbólico del más allá de la muerte.

Editado originalmente en francés por Catherine Goldstein y Jean-Luis Schlegel en 2007, con el título Vivant jusqu'a la mort suivi de fragments, el texto expone dos grupos de documentos. El primero (1995-1996) titulado "Hasta la muerte. Del duelo y de la alegría", y el segundo (2004-2005) "Fragmentos". Este segundo corpus discursivo, contiene material con y sin título.

El trayecto y propuesta de lectura nos introduce a la obra, con un Prefacio de Olivier Abel que sitúa las problemáticas desarrolladas por Ricoeur en los textos agrupados como ya indicamos. De este modo, aparecen señalizadas las reflexiones sobre el tiempo de la escritura asociado al tiempo mortal y el tiempo de la publicación desde donde arranca el tiempo de la obra en una perdurabilidad ignorante de la muerte. Este tópico parece suficiente para echar a andar un pensamiento filosófico profundo cuya meditación central se desarrolla en torno a la muerte. Las tres cuestiones o tópicos respecto a los cuales se desarrolla esta meditación y que articulan los documentos de 1995-1996 son: Las figuras de lo imaginario, Del duelo y de la alegría y iAún soy cristiano? Sobre estos tres elementos volveremos más adelante, ya que es necesario considerar previamente que el 
tono de su escritura conserva la vitalidad de la filosofía de la voluntad diseñada y desarrollada por Ricoeur desde la década del 50', plasmada finalmente en La Mémoire, l'histoire, l'oubli (2000). La clave fundamental de esta postura filosófica se traduce en el permanente estado agónico respecto de la vida, como un hambre de vivir que involucra la fratemidad sin olvidar la búsqueda de ser sí mismo. Como señala Abel, Ricoeur opta sin cesar por el deseo de vivir. Desde esa actitud vital, el autor se hace cargo de los tópicos centrales señalados antes y que constituyen su meditación sobre la muerte.

En el conjunto de documentos titulados: "Hasta la muerte: Del duelo y de la alegría", recoge tres grandes significaciones de la muerte, para tomar distancia de ellas y poder finalmente desligarse de sus cargas simbólicas. La primera de estas significaciones tiene que ver con la muerte de los otros y las múltiples preguntas que los que siguen vivos hacen respecto a este hecho. Dicho cuestionamiento o conjunto de interrogantes deben ser exorcizadas, ya que toda significación al respecto, es una significación de sobrevivientes que se preguntan si también los muertos siguen existiendo. Se trata de una obsesión del antefuturo innecesaria, ya que aunque tendremos que morir, no sabemos ni cuándo ni cómo (mors certa, hora incerta). La segunda significación de la muerte tiene que ver con la propia palabra muerte, en su sentido de pasar, finalizar o terminar. Sobre este segundo aspecto, el sobreviviente debe hacer el duelo de la separación del difunto que se aparta del vivo para que éste sobreviva. Nuevamente el filósofo enfatiza en su reflexión la condición del aún vivos. Toda la capacidad de pensamiento debe orientarse a dicho estado, hacia la movilización de los recursos más profundos de la vida para seguir afirmándose. En ese contexto-trance recurre al concepto de agonizante, aún vivo, que apela a esos recursos profundos de la vida. Allí se encuentra la epifanía de lo Esencial. La lucha de la vida hasta la muerte. En el desarrollo de esta línea reflexiva Ricoeur recurre al testimonio de Jorge Semprún ( $\mathrm{La}$ escritura o la vida 1994), como sobreviviente de los campos de deportación, en donde narra la muerte de Maurice Halbwachs (Buchenwald 1944). De esta experiencia, lo significativo tiene que ver con la compañía que Semprún da a Halbwachs y por tanto, de la amistad en el morir acompañado. En ese proceso aflora lo Esencial: la dignidad, la humanidad vencida pero incólume. La tercera configuración imaginaria o significación simbólica tiene que ver con la muerte como personaje activo. Cuestión planteada por los sobrevivientes respecto de los muertos: ivive aún, en otra parte, de otra manera? Esta tercera reflexión-meditación sobre la muerte se vincula con lo sucedido en los campos de concentración y exterminio. En ese contexto, moribundos y muertos conforman una sola Masa indistinta (en términos de Agustín, una massa perdita). Ricoeur comprende esta máquina de la muerte, auxiliado por el testimonio de Semprún, como la oposición del Mal absoluto a la fraternidad. Hechos estos alcances, el pensador vuelve al eje central de su tercer imaginario o significación simbólica para sentenciar que Toda muerte extermina. Esta sentencia centrada en la modalidad del exterminio no puede ser entendida por el solo hecho de morir, sino que por la acción del Mal.

La meditación de Ricoeur articulada sobre los elementos que antes hemos sintetizado, debe ser entendida como proyección de la imaginación, proyección simbólica 
que se puede desdoblar desde infinitos pliegues de sentido. No está en juego en este ejercicio, la experiencia propia, sino el infinito desarrollo de sistemas de significación, siempre a destiempo, siempre inminente. En tal sentido, el Duelo al que invita este pensador, es respecto a nuestra condición de víctimas de lo imaginario. Este es el exorcismo fundamental al que se nos llama y que finalmente será la motivación central de todo el texto. El autor pone su esfuerzo en entender que la nuda angustia de vivir se manifiesta a la sombra de lo imaginario de la muerte.

Hacia el final de este primer grupo de documentos ("Hasta la muerte: Del duelo y de la alegría"), el pensador orienta sus meditaciones sobre su muerte. Utilizando el concepto de desapego de Eckhart, llega la renuncia a las proyecciones imaginarias del sí identitario tras la muerte propia. Su reflexión comienza de esta forma, a tocar los límites del lenguaje, y por tanto, los límites del accionar del imaginario simbolizado y simbolizante. Afirmaciones como la siguiente lo ratifican: la muerte es en verdad el fin de la vida en el tiempo común a mí, vivo, y a quienes me sobrevivirán. Las reflexiones posteriores adquieren el tono esencialmente humano de quien nos invita a transferir el amor por la vida al otro y también de amar al otro como nuestro sobreviviente. Esta línea de pensamiento que se va cerrando sobre el sí mismo, incluye la voz del exégeta jesuita Xavier-León Dufour expresada en su obra Face á la mort: Jésus et Paul (1979). Los análisis interpretativos de Dufour sirven a Ricoeur para plantearse la posibilidad de que el Reino de Dios ya está entre nosotros (Lucas 17,21), para quienes viven en la fe del Cristo resucitado, acto sublime de amor fraterno por el que se ha pasado de la muerte a la vida (Juan 5, 24). En tal caso se trataría de un existir, tal vez en la memoria de Dios (idea tomada posiblemente de A.N. Whitehead), que el autor señala no merecer. Nada espera en este sentido para él, para después de su muerte, finalizando esta parte de la meditación con una afirmación rotunda: Acepto no ser más.

Los documentos y papeles agrupados en la segunda parte del texto con el título "Fragmentos", tocan variados tópicos, siempre de sumo interés para el autor. Su exposición se advierte o sospecha inconclusa. Dentro de los tópicos tratados, destacan nuevamente sus reflexiones sobre el tiempo de vida recortado en el tiempo histórico y por otro lado, el tiempo de la obra perdurable más allá de la muerte. Esta reflexión tiene como referencia un cuadro de Watteau en el que se puede distinguir el nombre de la obra y su inmortalidad frente al período acotado de la existencia del propio artista. Desde esa perspectiva distingue el tiempo inmortal de la obra, del tiempo mortal del existente vivo, asociando este último al tiempo del retiro, al tiempo del desaparecer, de tener que desaparecer con la tristeza que ello implica. Sin embargo, en ese estado de precariedad absoluta, el filósofo vuelve su mirada hacia la obra y su tiempo inmortal o angélico que será recepcionada por otros seres vivos en su tiempo propio y con ello la experiencia de estar vivo cobrará toda su plenitud y su potencia creadora.

Un segundo grupo de documentos destacable, (titulado Fragmento I), se refiere a su elección continua respecto al cristianismo. Esta elección se presenta como una adhesión, más que como fe. Se trata, plantea el autor, de una adhesión al cristianismo, que implica 
el apego a una figura personal bajo la cual el Infinito, el Altísimo se da a amar. Ricoeur avanza un poco más en las raíces de esta adhesión, haciendo alusión a sus herencias culturales. De este modo, su relación con la figura y persona de Jesús se establece a partir del conocimiento de textos canónicos, pertenecientes a la tradición evangélica reformada. En este sentido señala finalmente: Nada de fe inmediata.

El resto de papeles y documentos son muy breves y podrían ser la expresión de un filósofo debilitado físicamente. Sin embargo, hacia el final del texto hay una referencia a Jaques Derrida y su proyecto filosófico. Sobre este punto, se manifiesta de manera enérgica para afirmar su distancia definitiva de la deconstrucción. Cualquier adhesión hacia ella constituiría, señala Ricoeur, pedirme que muera. El autor no puede comprometer fidelidad alguna, con un proyecto filosófico que, a su juicio, está vinculado a una revolución desgarradora y total del lenguaje que expresa un signo de narcisismo verbal. Esta afirmación le sirve para reafirmar ya por última vez, su interés de que su obra sea entendida como huella para los otros (los míos en términos del filósofo), sus sobrevivientes, forma de que dicha obra y legado viva en el tiempo inmortal.

Aún cuando el texto reseñado no tiene la extensión y desarrollo minucioso de los temas abordados en la obra más significativa de Ricoeur, no deja de constituir una reflexión, como siempre iluminadora, sobre un tema que de una u otra forma está en todo el pensamiento filosófico, desarrollado de manera más o menos sistemático y también con mayor o menor obsesión. Sólo nos resta recordar, cuál es el mensaje de este pensador, qué nos quiere decir finalmente, más allá del esfuerzo discursivo y retórico. Al hacernos esta pregunta, no podemos dejar de pensar en Levinas, y con ello, interpretar este ejercicio expresado como conjunto de meditaciones sobre la muerte, en relación directa con la vida, con el valor de la vida en su dimensión agónica, desde esa hambre de vivir individual y fraternal. La postura de Ricoeur, como la de Levinas, corresponde a la de los seres contra la muerte que ven en esta la imposibilidad de toda posibilidad. El duelo al que nos invita Ricoeur tiene como correlato la retirada del armazón metafórico que da expresión al imaginario sobre la muerte, simplemente para vivir entendido como lo esencial. La muerte, la individual, no debe proyectarse como una sombra simbólica que oscurezca la plenitud de la vida, obstaculizando simultáneamente la posibilidad de entender el sentido del sí mismo y de compartir con el prójimo la fraternidad más honesta del amor humano.

Jorge Brower (profesor brower@yahoo.es)

Professor de Castelhano da Faculdade de Humanidades da Universidade de Santiago do Chile. 